\title{
The influence of soil parameters on the impulse and airblast overpressure loading above surface-laid and shallow-buried explosives
}

\author{
John Q. Ehrgott, Jr.*, Stephen A. Akers, Jon E. Windham, Denis D. Rickman and Kent T. Danielson \\ Impact and Explosion Effects Branch, Geotechnical and Structures Laboratory, US Army Engineering Research \\ and Development Center, Vicksburg, MS, USA
}

Received 23 February 2010

Revised 7 June 2010

\begin{abstract}
The dynamic airblast, fragmentation, and soil ejecta loading environments produced by the detonation of surface-laid and shallow-buried mines are major threats to lightweight military vehicles. During the past several years, the US Army has focused considerable attention on developing improved methods for predicting the below-vehicle environment from these threats for use by vehicle/armor analysts; thereby, improving the survivability of these platforms. The US Army Engineer Research and Development Center recently completed the first year of a three-year effort to experimentally and numerically quantify the blast and fragment loading environments on vehicles due to surface and subsurface mine and IED detonations. As part of this research effort, a series of experiments was conducted to quantify the effects of soil parameters on the aboveground blast environments produced by the detonation of aboveground bottom-surface-tangent, buried top-surface-tangent, and shallow-buried 2.3-kg (5-lb) Composition $\mathrm{C} 4$ charges. The experiments were conducted using three different well characterized soils; $10.8 \%$ air-filled-voids (AFV) silty sand, 5.4\% AFV clay, and 29.8\% AFV poorly graded sand. The combined aboveground loads due to airblast and soil debris were measured by an impulse measurement device. The near-surface airblast overpressure was quantified by a series of side-on measurements above the charges at one elevation and three radial distances. This paper summarizes and compares the results of the experimental program with emphasis on defining the effect of soil parameters on the aboveground blast environment.
\end{abstract}

\section{Introduction}

Detonation of an explosive charge, such as a mine or an improvised explosive device (IED) at the ground surface or buried at shallow depth in soil, can produce high airblast pressures and significant dynamic soil debris loads on an overlying structure, such as a vehicle passing over the explosive. The blast loading environment is a function of many factors including the explosive type, configuration, mass, and depth of burial, soil characteristics, and the distance between the ground surface and the target structure.

A buried explosive that detonates and interacts with an aboveground structure typically produces complex responses and interactions. The explosive detonation produces extremely high pressure gases that expand to volumes hundreds of times greater than the initial volume of the explosive charge in order to reach an equilibrium pressure condition. As the detonation gases begin to expand, the confined soil below the explosive charge is severely compressed, even to the point that individual soil grains are pulverized. Meanwhile, the soil overlying the explosive charge, and to

\footnotetext{
*Corresponding author. E-mail: jay.q.ehrgott@usacc.army.mil.
} 
a lesser degree, the soil in the plane of the charge, is unconfined and accelerates outward, away from the charge center. For those cases in which only a thin layer of soil overlies the explosive, the soil directly above the detonation is projected upward with a velocity approximately equal to that of the expanding shock front. If the chassis of a vehicle is positioned over the detonation point, this high-velocity soil compresses the air between the original ground surface and the chassis to a small fraction of its initial volume. The highly-compressed air loads the chassis, followed immediately by the impact of the high-velocity soil, the impact of the expanding detonation gas bubble, and the impact of any detonation residues entrained in the detonation gases. All of these materials intermix and produce extremely complex interfaces and interactions.

It is known that the different soil characteristics, such as moisture content [1], affect this complex load environment. At this time, it is unclear which soil parameter or parameters have the most significant effect on a shallow-buried blast and the resulting load environment above the charge. However, it has been shown that the energy released to an aboveground target by a buried mine varies greatly with the variations in soil conditions [2]. It has also been shown that for a detonation in a sandy soil, a large part of the damage to an aboveground target is a result of momentum transfer from the sand to the target [3]. It is not clear if the aboveground target is first impacted by the soil ejected above the charge or by the detonation products and airblast pressure created by the detonation. It is also not clear if the airblast impacting a target above is focused by a buried charge. There are some early experimental data by Wenzel and Esparza (1972) [4] that showed very little difference in the normal reflected peak pressure for a buried pancake charge compared to the same charge in air at a scaled distance of 0.3 to $1.0 \mathrm{ft} / \mathrm{lb}^{1 / 3}$. However, there are indications that the soil is a major contributor to the additional impulse loading created by the buried charge. This reinforces the need to understand the effects of the soil properties on this aboveground loading. A lot of the research to date was conducted with a dry sand because it is easier to place and more repeatable than tests conducted in wet, silty clay type soil [2]. Unfortunately, current research presents very little data on the soils' characterization and in-place conditions. In many cases, the soil conditions were based on visual approximations. This makes it very difficult to find the key mechanical properties for soils that affect this aboveground blast environment.

One trend shown in the literature was the effect of increased moisture. Wenzel and Esparza (1972) [4] showed that increasing the moisture content in the soil surrounding a shallow-buried charge increased the peak reflective pressure and impulse above the charge by a factor of over two. Although the soil type was not clearly identified in the literature, the soil was held constant for the experiments, and moisture content was increased from approximately $7 \%$ to $20 \%$. It was also shown that for a constant soil type and explosive depth of burial, there is a significant increase in energy transfer to an aboveground target with increased soil moisture content. This trend held true for both fine-grained and coarse-grained soils [2]. It was not clear in either of these references whether soil density was held constant during the tests. This increased loading with increased moisture seems to follow a similar pattern found in ground shock research. However, the mechanical properties associated with this increase are not identified. The literature also showed that fine-grained soils such as silts and clays seem to create a higher blast energy output on an aboveground target when compared to coarse-grained soils such as sands. These data were very limited, so it is difficult to make a clear comparison.

Research is needed to better understand the aboveground environment created by the detonation of a shallow-buried explosive. In order to design adequate protective measures for an aboveground structure, designers must understand the load environment created by these near-surface detonations. Unfortunately, there is no accurate methodology for predicting these airblast and soil debris loads to support the designs. Development of the required prediction tools is hampered by lack of well-documented experimental results for these complex loads. Without detailed experimental data, the numerical simulations of these loads cannot be adequately validated for the large deformation, stress, and motion gradients and the resulting interactions with structures.

To address the need for these data, the US Army Engineer Research and Development Center (ERDC) recently conducted a series of research experiments to quantify the influence of soil properties on the aboveground environment from the detonation of a bare explosive charge resting on the soil surface or shallow-buried. In order to fully quantify the influence of soil parameters, well-controlled experiments were designed to directly measure soil debris and airblast loadings on an aboveground reaction structure due to the detonation of explosives at the surface of and shallow-buried in three very different soils. The experiments were performed using specifications and strict quality controls that limited the influence of outside variables and ensured repeatability of the experiments. The experiments provided blast pressure, soil stress, and impulse data from each soil type. These data were analyzed to investigate the influence of the different soil types on the aboveground environment. 


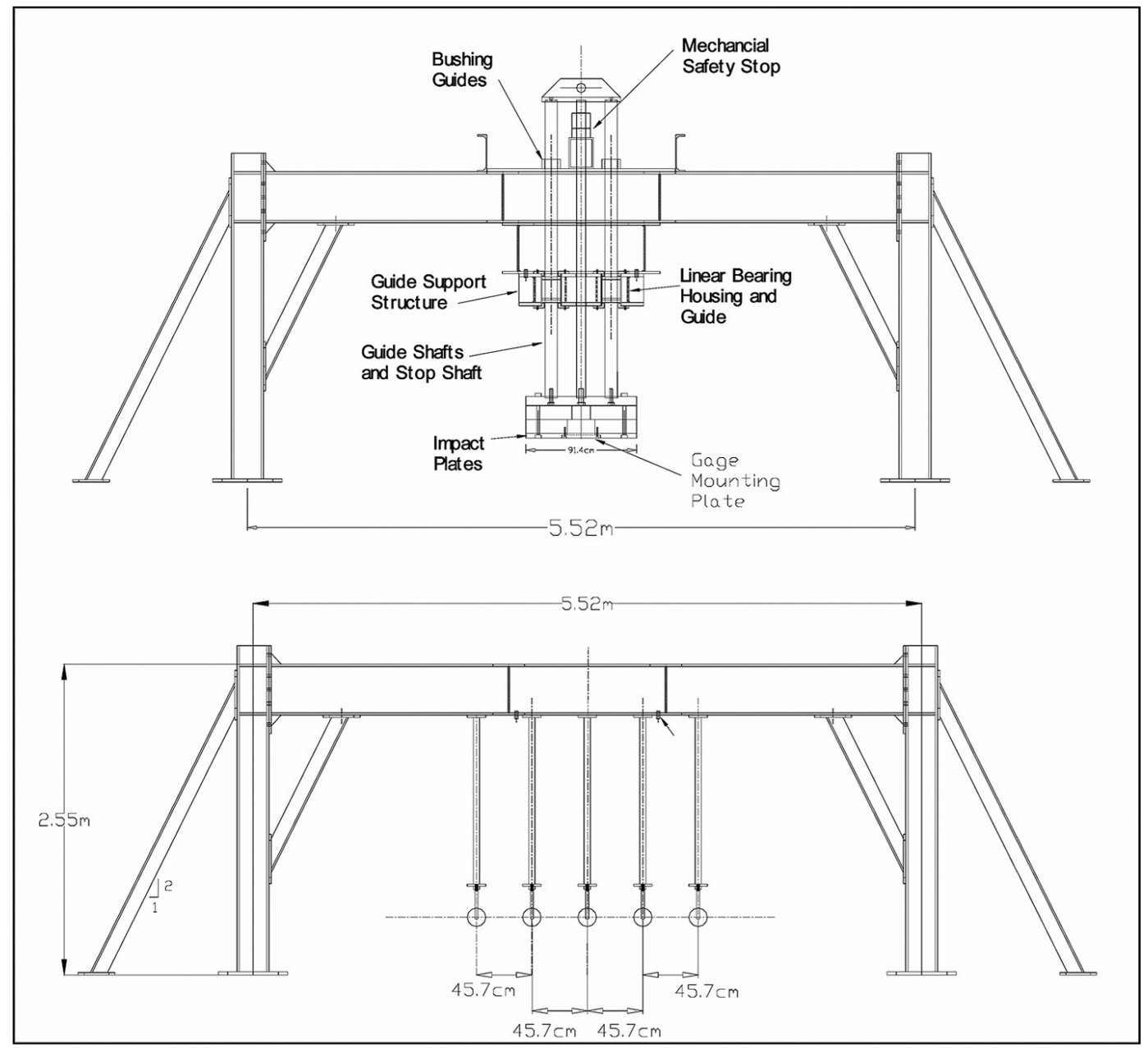

Fig. 1. Section view of impulse measurement device system (top) and the overpressure gage support system (bottom).

\section{Impulse and airblast measurement system}

As a part of the research program, ERDC designed, fabricated, and fielded an Impulse Measurement Device (IMD) and a side-on overpressure gage support frame for capturing the blast loading conditions above a shallow-buried charge. The system was designed to minimize both the global movement and the vibration of the structure when subjected to the blast environment produced from either surface-laid or shallow-buried bare-explosive charges. The system has two configurations; the first is intended to measure velocity, and thus the impulse imparted to a piston assembly (Fig. 1 - top), and the second is used to make side-on overpressure measurements at five fixed locations (Fig. 1 - bottom).

The basic principle behind the piston assembly is to capture the vertical movement (velocity) of a known mass with a known impact surface area that can then be used to derive the imparted impulse loads. This impulse, captured by the IMD, is the combination of both the airblast pressures and the soil debris momentum loading. Prior to fielding the IMD, a series of calibration tests was conducted to check the frictional resistance in the piston assembly and verify the displacement and velocity results captured by the system.

The IMD piston assembly is removed from its support frame when the system is configured to make side-on overpressure measurements. Mounts for the pressure gages are held in place by V-shaped steel brackets attached to the bottom of the support frame (Fig. 1 - bottom). The horizontal distance between each of the five gages is $46 \mathrm{~cm}$ (18 in.). 
Table 1

Experimental constants

\begin{tabular}{ll}
\hline Description & Constant value \\
\hline Charge Mass & 5 lbs \\
Charge Shape & Cylinder \\
Charge Geometry & 2.3 -in. ht x 6.9-in. diam. \\
Explosive Type & C4 \\
Standoff Distance & 20-in. (top of charge to measurement surface) \\
\hline
\end{tabular}

The design blast loading environment for the support structure was based on a $4.5 \mathrm{~kg}(10 \mathrm{lb}) \mathrm{C} 4$ aboveground explosive charge. The maximum vertical motion of the sliding piston assembly is $66 \mathrm{~cm}$ (26 in.). This maximum travel and the mass of the piston assembly limit the maximum explosive mass of a buried bare charge to approximately $2.3 \mathrm{~kg}(5 \mathrm{lb})$ of $\mathrm{C} 4$ at a standoff distance of $51 \mathrm{~cm}(20 \mathrm{in}$.). For this program, standoff was defined as the distance from the top surface of the charge to the bottom of the impact plate on the piston assembly or the sensor face of the central side-on overpressure gage. The same standoff was used in all of the experiments.

\section{Experimental plan}

Key factors that appear to affect the blast loading on a structure above a surface-flush or shallow-buried charge include the standoff distance from the charge, the explosive charge size and mass, the charge shape, the type of explosive, depth of burial below the surface, and the surrounding soil properties and soil conditions [5]. For the experiments conducted during this program, the primary focus was the effects of soil properties on the blast environment. Therefore, the experimental program was designed to reduce the effects of as many of the key parameters as possible. The key factors held constant included the charge mass, charge shape, charge geometry, explosive type, and standoff distance. Table 1 lists the experimental constants and the values selected for the experiments.

The primary variables for the experimental program included the soil type in which the charge was buried and the depth of burial. The experiments were conducted using three different soil types that bound the effects of soil on the blast environments. The depth of burial selected was based on a common depth for buried mines. Based on the two variables selected, a test matrix was developed in an attempt to gather as much experimental data as possible with the funds available. Table 2 shows the experimental matrix that was developed and the variables selected for each experiment.

\section{Experimental configuration}

The experimental configuration consisted of three test series, each conducted on a different soil type. The three soil types selected included a $10.8 \%$ air-filled-voids (AFV) silty sand, or intermediate soil, for one test series, a 5.6\% AFV wet clay soil for the second test series, and a $29.8 \%$ AFV dry sand soil for the third test series. Each of the three test series consisted of five experiments. Two of the experiments were conducted using the IMD in order to measure total impulse imparted to the piston assembly, referred to as the IMD layout. The layout for the two IMD experiments consisted of a charge detonated on the surface of the testbed and a charge detonated at a depth of 4 in. below the surface of the testbed. For both experiments, the standoff distance between the top of the charge and the impact plate of the IMD piston assembly was held constant at $20 \mathrm{in}$. The geometry and configuration of the two IMD experiments is presented in Fig. 2.

The three remaining experiments in each test series were conducted using a series of five side-on overpressure gages above the testbed surface, referred to as side-on layout as shown in Fig. 3a. The layout for the three side-on experiments consisted of one with the charge detonated on the surface, i.e., tangent surface above (TSA), one with the charge buried with its top surface flush with the top surface of the testbed, i.e., tangent surface below (TSB), and one with the charge detonated at a depth of 4 in. below the surface of the testbed (Fig. 3b). For all three experiments, the standoff distance between the top of the charge and a horizontal plane through the side-on gages 
Table 2

Experimental matrix

\begin{tabular}{lcccccc}
\hline $\begin{array}{l}\text { Test } \\
\text { Number }\end{array}$ & $\begin{array}{c}\text { Charge } \\
\text { Mass (lbs) }\end{array}$ & $\begin{array}{c}\text { Soil } \\
\text { Type }\end{array}$ & $\begin{array}{c}\text { Charge } \\
\text { Position }\end{array}$ & $\begin{array}{c}\text { Depth of } \\
\text { Burial (in.) }\end{array}$ & $\begin{array}{c}\text { Target } \\
\text { Standoff (in.) }\end{array}$ & Test Configuration \\
\hline BM-I-01 & 5 & SM & TSA & - & 20 & Side-on Overpressure \\
BM-I-02 & 5 & SM & TSB & - & 20 & Side-on Overpressure \\
BM-I-03 & 5 & SM & Buried & 4 & 20 & Side-on Overpressure \\
BM-I-04 & 5 & SM & TSA & - & 20 & IMD \\
BM-I-05 & 5 & SM & Buried & 4 & 20 & IMD \\
BM-C-01 & 5 & CL & TSA & - & 20 & Side-on Overpressure \\
BM-C-02 & 5 & CL & TSB & - & 20 & Side-on Overpressure \\
BM-C-03 & 5 & CL & Buried & 4 & 20 & Side-on Overpressure \\
BM-C-04 & 5 & CL & TSA & - & 20 & IMD \\
BM-C-05 & 5 & CL & Buried & 4 & 20 & IMD \\
BM-S-01 & 5 & SP & TSA & - & 20 & Side-on Overpressure \\
BM-S-02 & 5 & SP & TSB & - & 20 & Side-on Overpressure \\
BM-S-03 & 5 & SP & Buried & 4 & 20 & Side-on Overpressure \\
BM-S-04 & 5 & SP & TSA & - & 20 & IMD \\
BM-S-05 & 5 & SP & Buried & 4 & 20 & IMD \\
\hline
\end{tabular}

Notes: Soil Type: CL for Silty Clay, SM for Clayey Sand, and SP for Poorly Graded Sand per the Unified Soil Classification System.

Charge Positions: TSA for Tangent Surface Above and TSB Tangent Surface Below.

Depth of Burial is measured from top of charge to ground surface.

Target standoff is measured from top of charge to bottom of IMD or centerline of side-on overpressure gages.

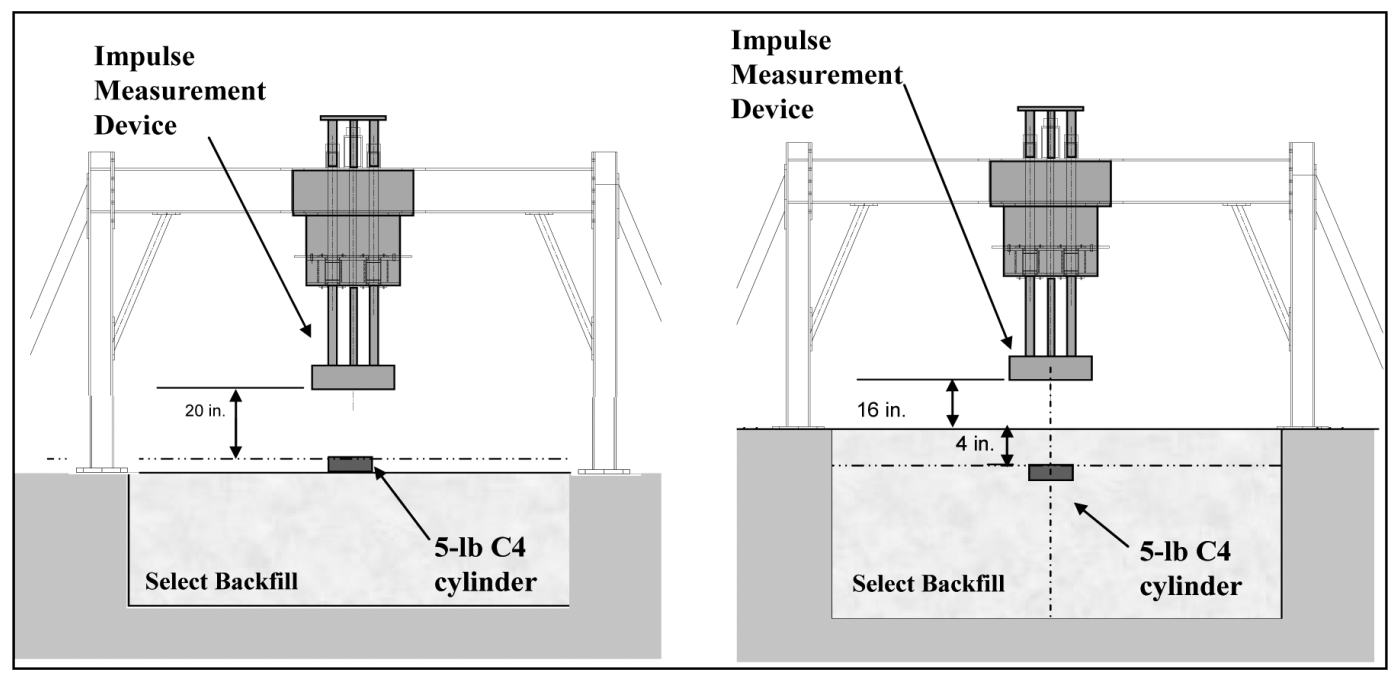

Fig. 2. Layout for the IMD experiments.

was held constant at $20 \mathrm{in}$. The side-on overpressure gages were located in line with one gage directly above the charge, two with a horizontal offset of $18 \mathrm{in}$., and two with a horizontal offset of $36 \mathrm{in}$. All five gages were located at the same elevation above the testbed that matched the vertical standoff used for the IMD. Figure 3 shows a detailed layout of the side-on overpressure gages located relative to the charge and the geometry and configuration of the three side-on overpressure experiments.

\section{Soil backfill materials and testbed construction}

Results of grain-size distribution and classification tests [6] for the three backfill materials are shown in Fig. 4. The intermediate soil classified according to the Unified Soil Classification System [7] as a silty sand (SM) with 


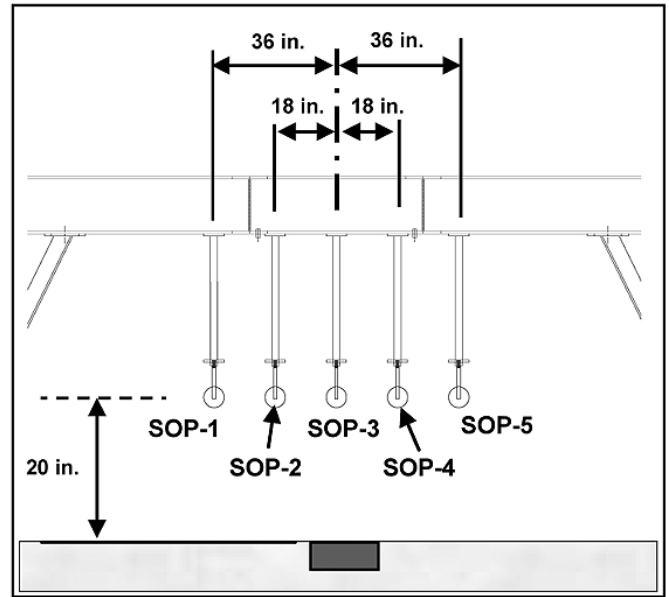

(a) Layout for side-on overpressure gages.
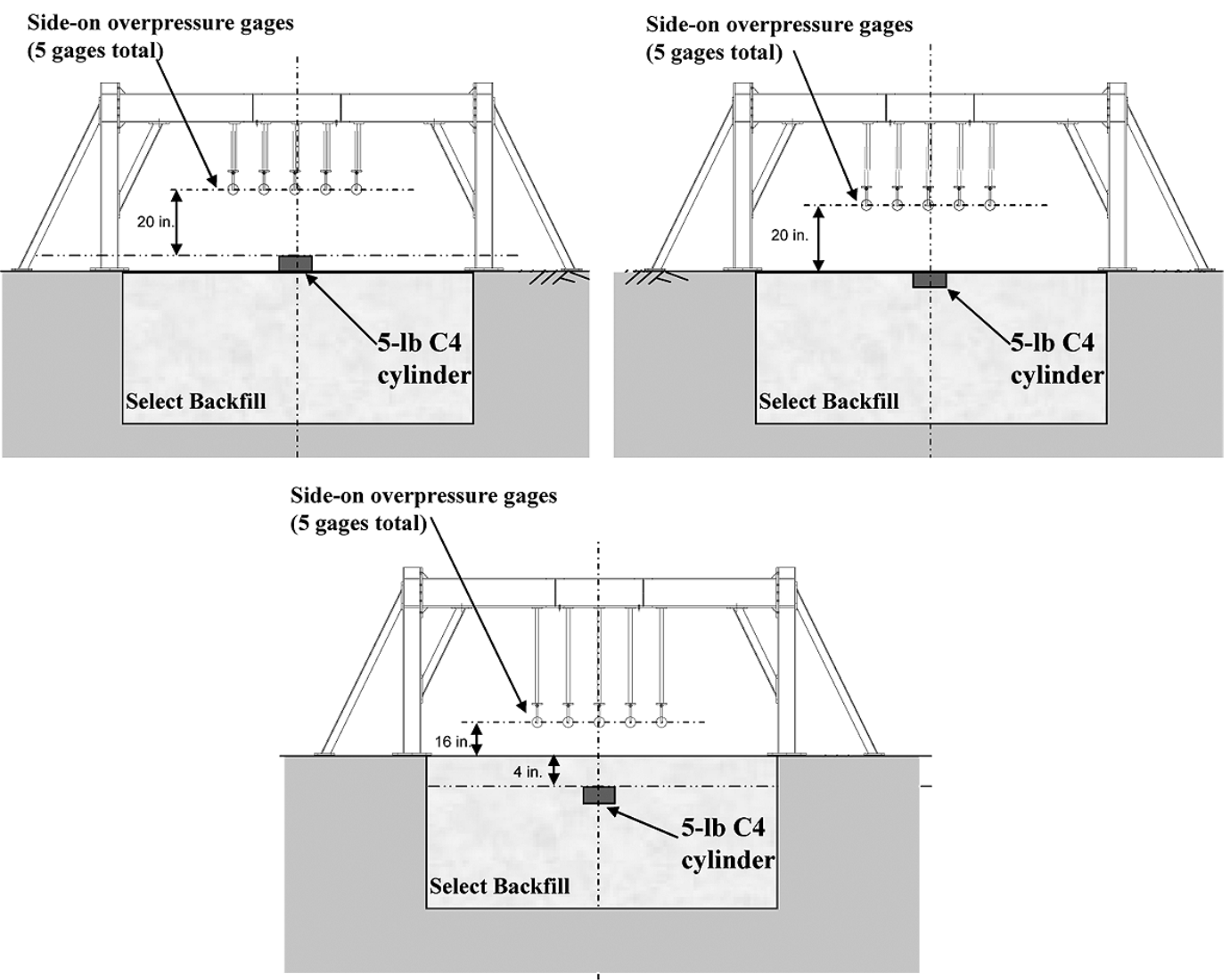

(b) Side-on gage experimental layout.

Fig. 3. Layout for the side-on overpressure gages and the experiment layout. 


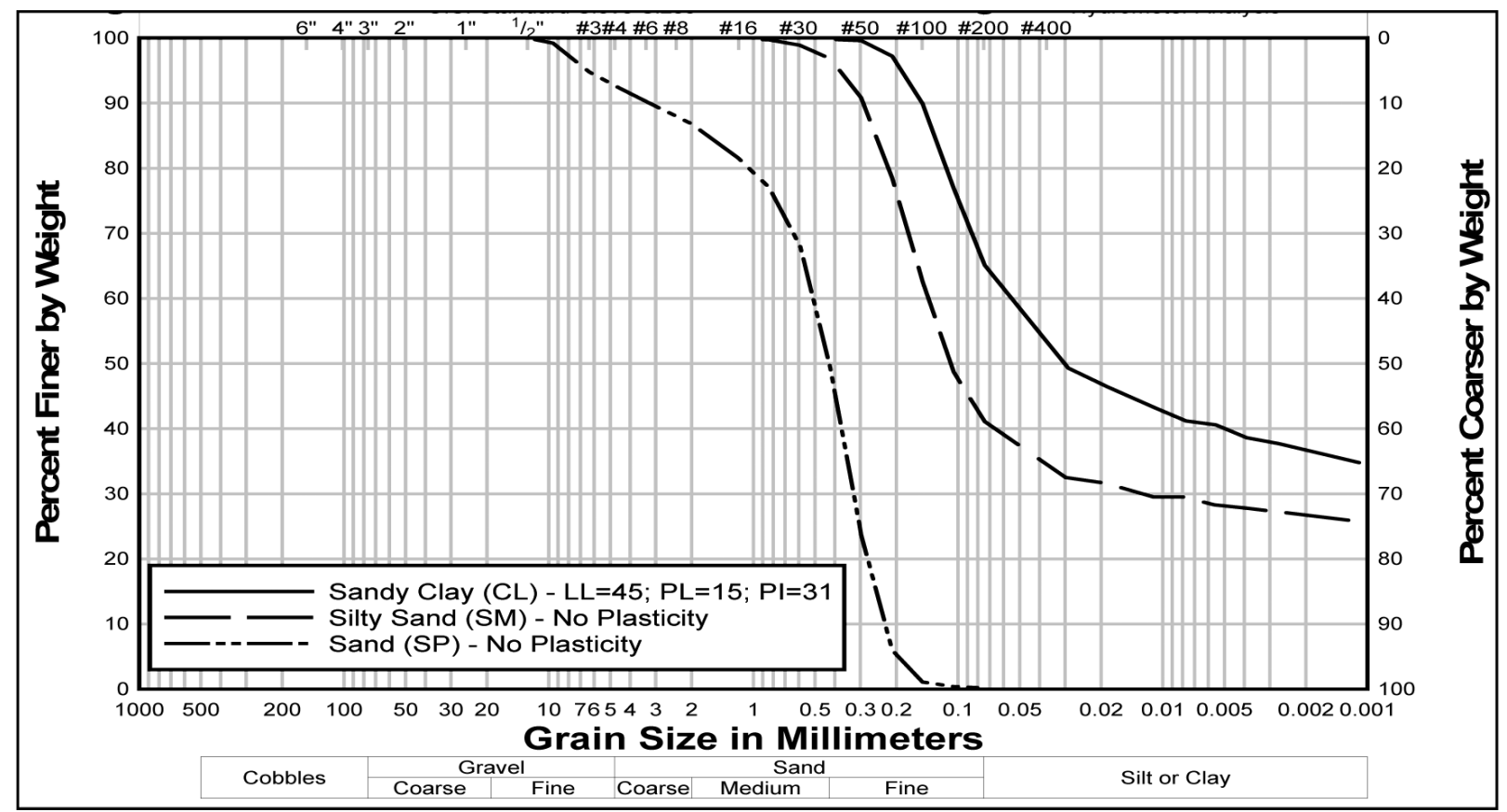

Fig. 4. Grain-size distributions and Atterberg limits for backfill soils.

a specific gravity of soil solids of 2.69; the clay material classified as a sandy clay (CL) with a specific gravity of 2.72; and the dry sand material classified as a poorly graded sand (SP) with a specific gravity of 2.67. The basis for the selection of each backfill material and its respective target as-placed values of water content and dry density is documented in Ehrgott [8-10] along with the results of all quality control tests and mechanical property tests conducted on the backfill materials. The testbeds were constructed in an excavation surrounded by the native soil and located below the IMD side-on gage support structure. The testbed size was approximately $12 \mathrm{ft}$ by $12 \mathrm{ft}$ by $4 \mathrm{ft}$ 6-in.-deep. The size was selected to minimize boundary effects between the native soil and the select backfill on the impulse delivered to the IMD or side-on pressure gages.

The backfills were placed in approximately 6- to 8-in. lifts and compacted to pre-selected values of density and water content for each soil type. In each lift, the quality control inspector made three to four measurements of wet density and water content with a nuclear moisture-density gage, obtained two samples of the material from the mid-depth for determination of microwave water contents, and four samples for standard oven-dry water contents. The microwave water content measurement was taken to insure that the water content of the material was within the target range specified before proceeding to the next lift. Determination of acceptance or rejection of each lift was based on calculated values of dry density and water content. Adjustments were made to the lift when values not conforming to specifications were found. A representative bulk sample of material was retained from each lift for use in subsequent grain-size distribution, classification, and mechanical property tests. The as-placed properties selected for the testbeds are presented in Table 3.

\section{Results from experiment}

Experiments were performed in the fall of 2008 and spring of 2009. The general geometry and configuration of the experiments were shown in Figs 2 and 3. The experiments were divided into three test series. The first test series used the intermediate $10.8 \%$ air-filled-voids silty sand backfill, the second test series used the $5.6 \%$ air-filled-voids wet clay backfill, and the third test series used the $29.8 \%$ air-filled-voids dry sand backfill. The detailed results from each test series are presented in Ehrgott (2010) [12]. Presented are results of backfill quality control tests, testbed crater surveys, time-histories of ground shock stress and particle velocity, ground surface overpressure, 
Table 3

As-placed soil parameters

\begin{tabular}{lcccccrrrr}
\hline Soil type & $\begin{array}{c}\text { Wet } \\
\text { density pcf }\end{array}$ & $\begin{array}{c}\text { Dry } \\
\text { density pcf }\end{array}$ & $\begin{array}{c}\text { Water } \\
\text { content } \%\end{array}$ & $\begin{array}{c}\text { Volume of } \\
\text { solids } \%\end{array}$ & $\begin{array}{c}\text { Volume of } \\
\text { water } \%\end{array}$ & $\begin{array}{c}\text { Volume of } \\
\text { air } \%\end{array}$ & $\begin{array}{c}\text { Silt/ } \\
\text { clay } \%\end{array}$ & $\begin{array}{c}\text { Sand } \\
\%\end{array}$ & $\begin{array}{c}\text { Permeability* } \\
\text { cm/sec }\end{array}$ \\
\hline Intermediate & 125.4 & 110.9 & 13.0 & 66.1 & 23.1 & 10.8 & 42 & 58 & $10^{-3}$ to $10^{-5}$ \\
Clay & 121.2 & 98.4 & 23.1 & 58.0 & 36.4 & 5.6 & 65 & 35 & $10^{-5}$ to $10^{-7}$ \\
Sand & 109.8 & 105.6 & 4.0 & 63.4 & 6.8 & 29.8 & 0 & 100 & $10^{-1}$ to $10^{-3}$ \\
\hline
\end{tabular}

${ }^{*}$ From Jumikis [11, p. 271].

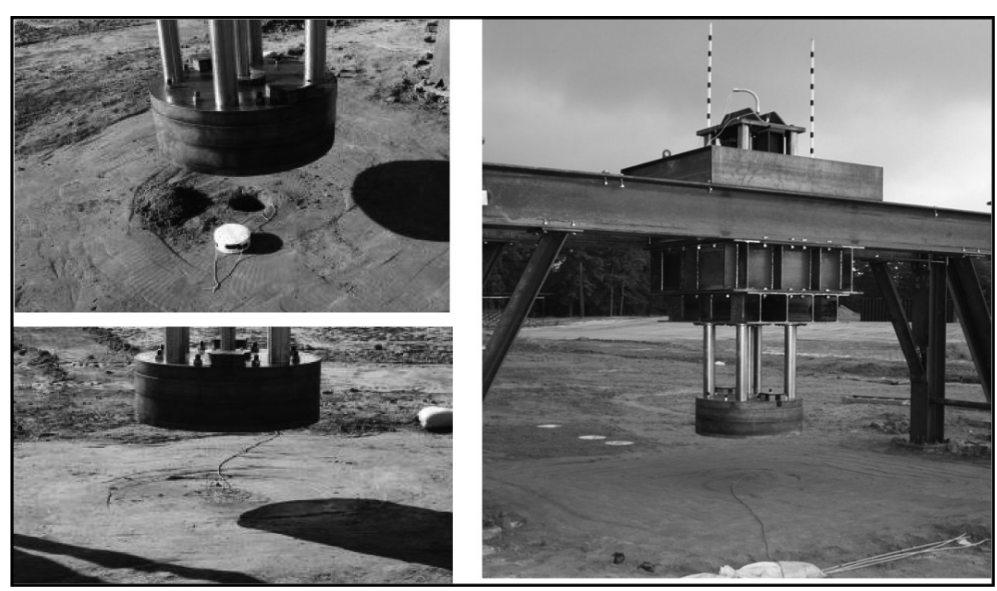

Fig. 5. Pretest photo of the IMD testbed.

side-on overpressure above the charge, and the responses of the IMD, which include high-speed video, displacement, motion, and total impulse. Figures 5 and 6 show pretest and posttest photographs, respectively, from one of the IMD experiments. Figure 7 shows snap shots at different times from the high-speed video illustrating the effects of the blast on the IMD. Data captured from the instrumentation and high-speed video indicated that the IMD functioned correctly and captured the impulse loading from the experiments.

\section{Comparison of experimental results}

\subsection{Craters}

For each of the experiments, pretest and posttest cross-sectional grade surveys were conducted along the primary axes ( 0 deg. to $180 \mathrm{deg}$. and $90 \mathrm{deg}$. to $270 \mathrm{deg}$.) through GZ. The surveys consisted of elevations taken at horizontal intervals of $6 \mathrm{in}$. on center across the crater. The first three experiments conducted for each backfill soil type had side-on overpressure gages located $20 \mathrm{in}$. above the explosive charges in the centers of the testbeds. These gages provided little if any interference with the ejecta emanating from the explosive-induced craters. The remaining two experiments in each series had the IMD device with its 3-ft diameter, 4-1/2-in.-thick steel plate located directly over the explosive charge. This plate did affect the trajectory of the out-flying ejecta, some of which probably fell back into the crater, which would affect posttest crater measurements. Hence, the crater comparisons shown here only used the results from the first three experiments of each test series.

Figure 8 compares the crater cross-sections obtained from experiments BM-I-01, BM-C-01, and BM-S-01 from the intermediate soil, clay, and sand backfill testbeds, respectively, in which the explosive charge for each was placed tangent surface above the respective testbeds. The crater produced in the wet clay testbed was the deepest of the three craters and had steep sides. The crater produced in the dry sand testbed had the shallowest depth and much flatter side slopes. The intermediate soil produced a crater with steep sides but was not as deep as the wet clay craters. The wet clay inherently has more cohesion than the other two soils, which accounts for the steep crater side walls. Also, 


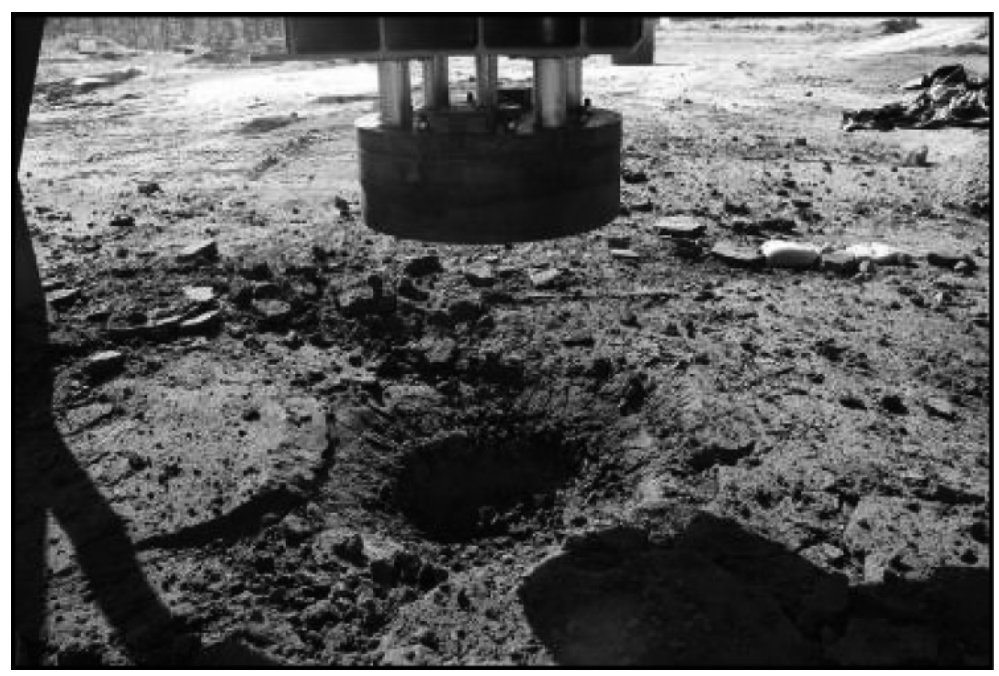

Fig. 6. Posttest photo of the IMD testbed.

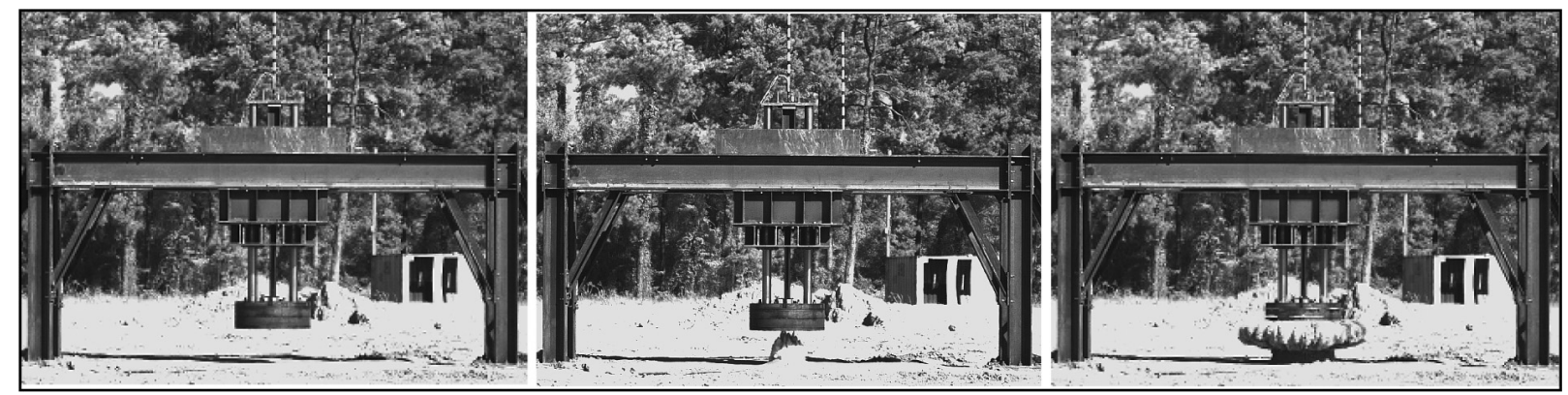

Fig. 7. Captured frames from high-speed video of an IMD experiment.

the wet clay with its lowest air voids content and lowest maximum shear strength will propagate a higher level of ground shock into its testbed than the other two materials, which accounts for its deeper crater depth. On the other hand, the dry sand had the highest air voids content and highest shear strength, causing craters in the sand to be the shallowest. The slopes of the crater sidewalls were approximately equal to the sand's angle of friction.

Figure 9 compares the crater cross-sections obtained from experiments BM-I-02, BM-C-02, and BM-S-02 from the intermediate soil, clay, and sand backfill testbeds, respectively, in which the explosive charge for each was placed tangent surface below the respective testbeds. The same trends discussed above for the tangent surface above experiments are shown again here. The primary differences in these craters are that the crater depths and surface diameters are larger for the tangent surface below explosive charge. This is due to the increased coupling of the explosive energy into the testbed soils for the partially buried case.

Figure 10 compares the crater cross sections obtained from experiments BM-I-03, BM-C-03, and BM-S-03 from the intermediate soil, clay, and sand backfill testbeds, respectively, in which the explosive charge was buried 4 in. below the surface of the respective testbeds. Again, the same trends discussed above for the tangent surface experiments are shown in the figure, and again, the sizes of the craters are even greater for the fully-buried explosive charge case due an even greater increase in coupling of the explosive energy.

\subsection{Side-on overpressure impulse}

The primary purpose of the side-on overpressure measurements was to obtain pressure time-histories from which airblast impulse could be calculated. Figures 11, 12, and 13 show the peak side-on overpressure impulse data versus 


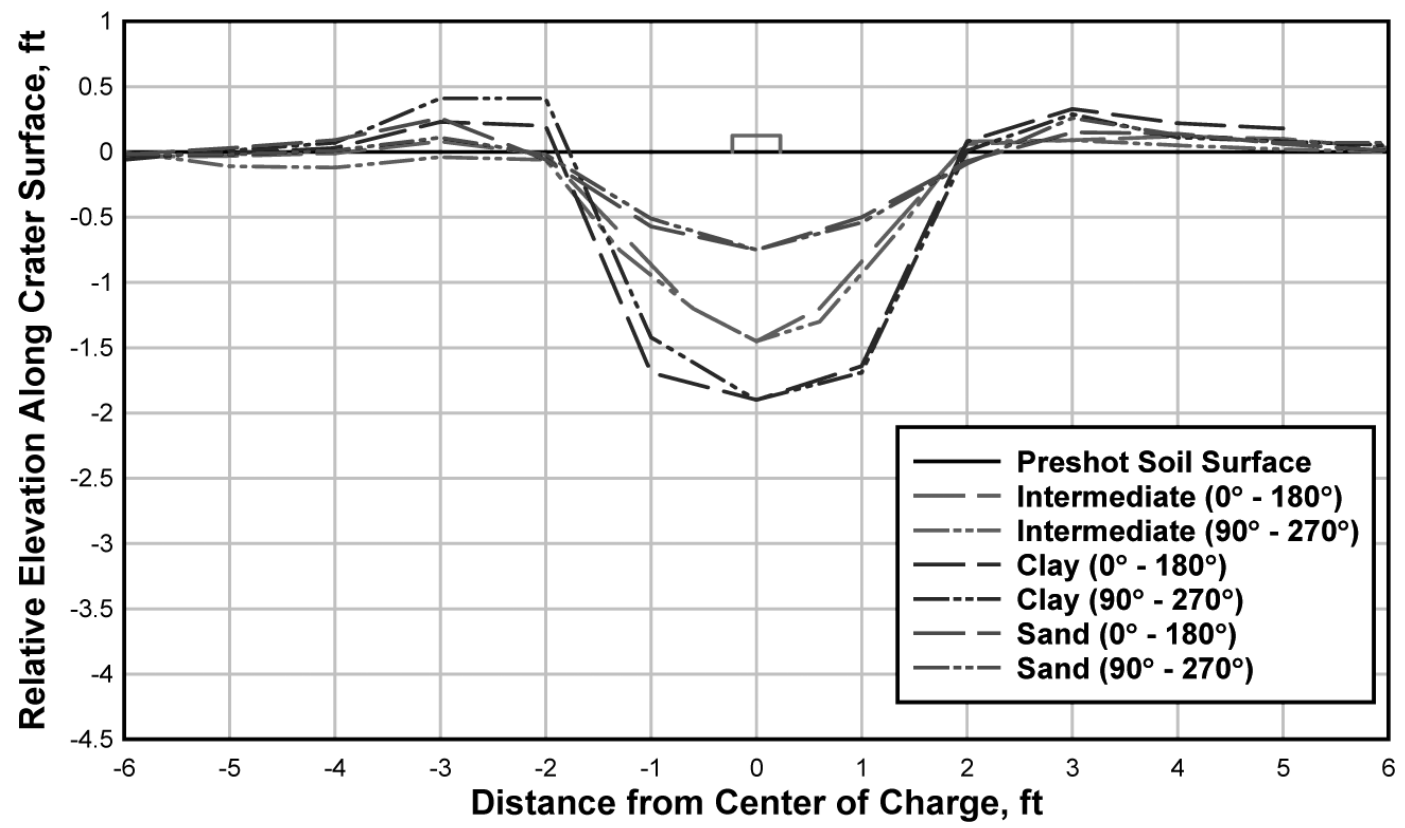

Fig. 8. Crater profiles from three experiments with the charge placed tangent surface above.

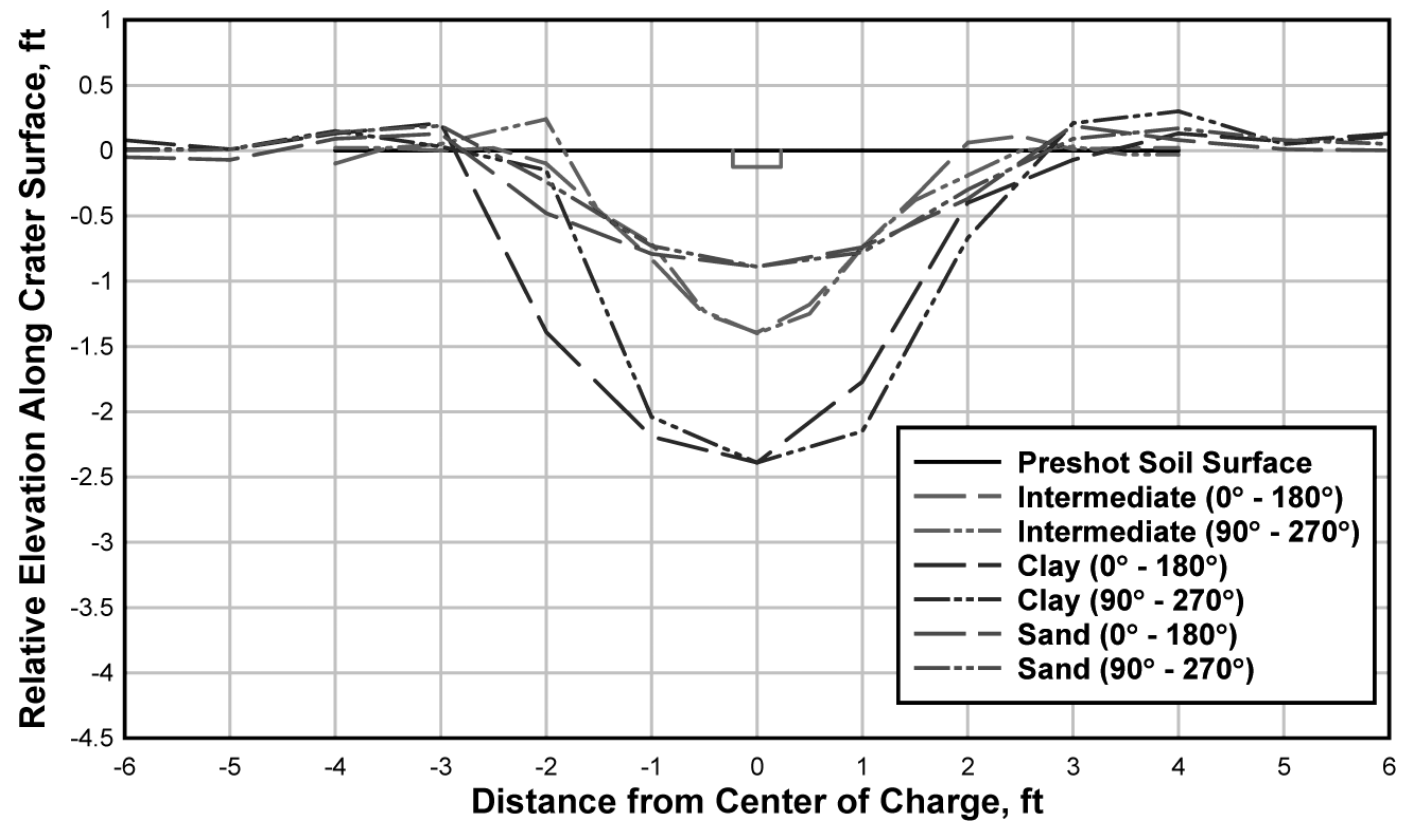

Fig. 9. Crater profiles from three experiments with the charge placed tangent surface below.

range (distance from center of charge) for the cases of the explosive charge placed tangent surface above the testbed, tangent surface below the testbed, and buried 4 in. below the surface of the testbed, respectively. For the tangent surface above case, Fig. 11, at the closest range, the peak impulse from experiment BM-S-01, the sand backfill testbed, produced the highest impulse followed by that from the experiment with the intermediate silty sand testbed and then the clay testbed. At the 28- and 42-in. ranges, all of the peak impulse values decrease significantly to about the same range of values. At the closest range for the surface tangent below case, Fig. 12, the measured peak 


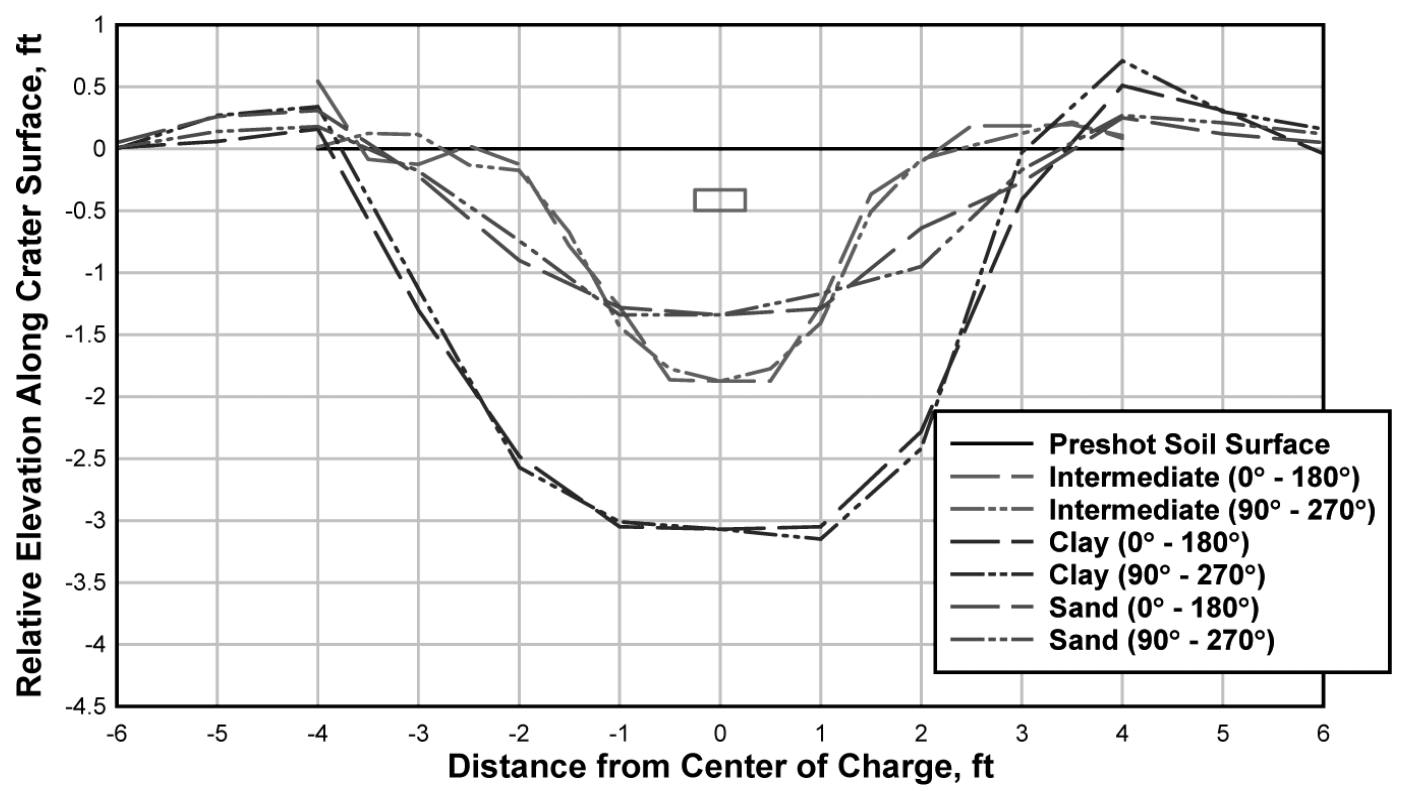

Fig. 10. Crater profiles from three experiments with the charge buried 4 in.

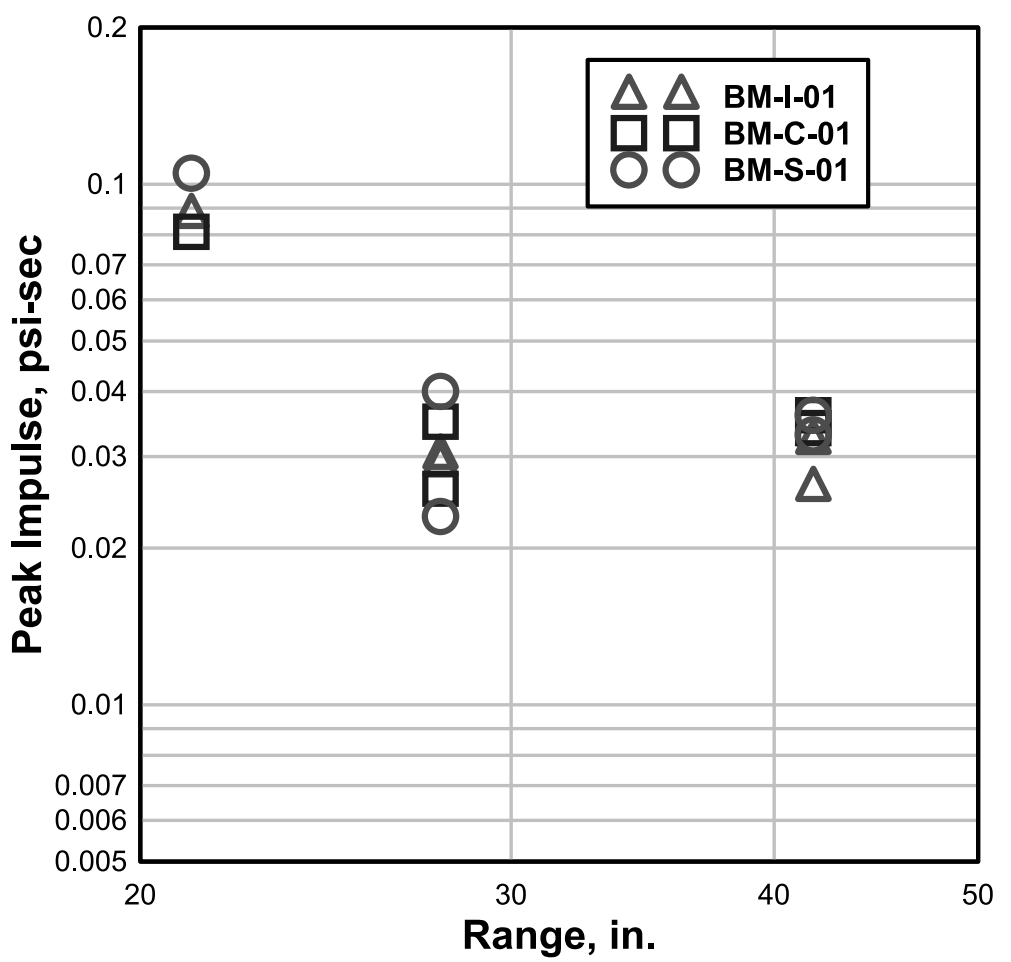

Fig. 11. Peak side-on overpressure impulse for the charge placed tangent surface above.

impulse for the clay testbed was slightly greater than that for the sand testbed. No measurements were obtained for the intermediate soil case at this range. Over the 21 to 42-in. ranges, all peak impulse values decayed and are not significantly different regardless of soil type. For the case of the buried charge shown in Fig. 13, the measured peak impulse for the sand testbed at the closest range was slightly greater than that for the intermediate and clay testbeds. 


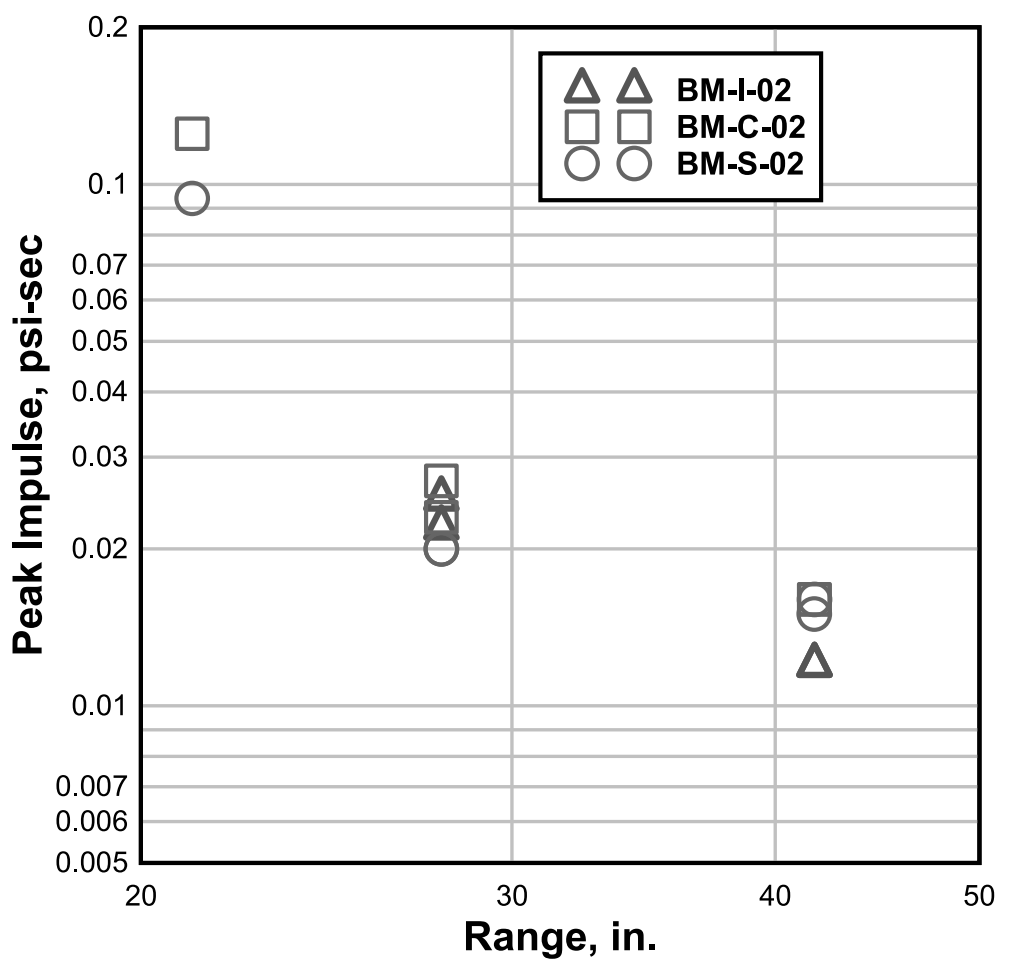

Fig. 12. Peak side-on overpressure impulse for the charge placed tangent surface below.

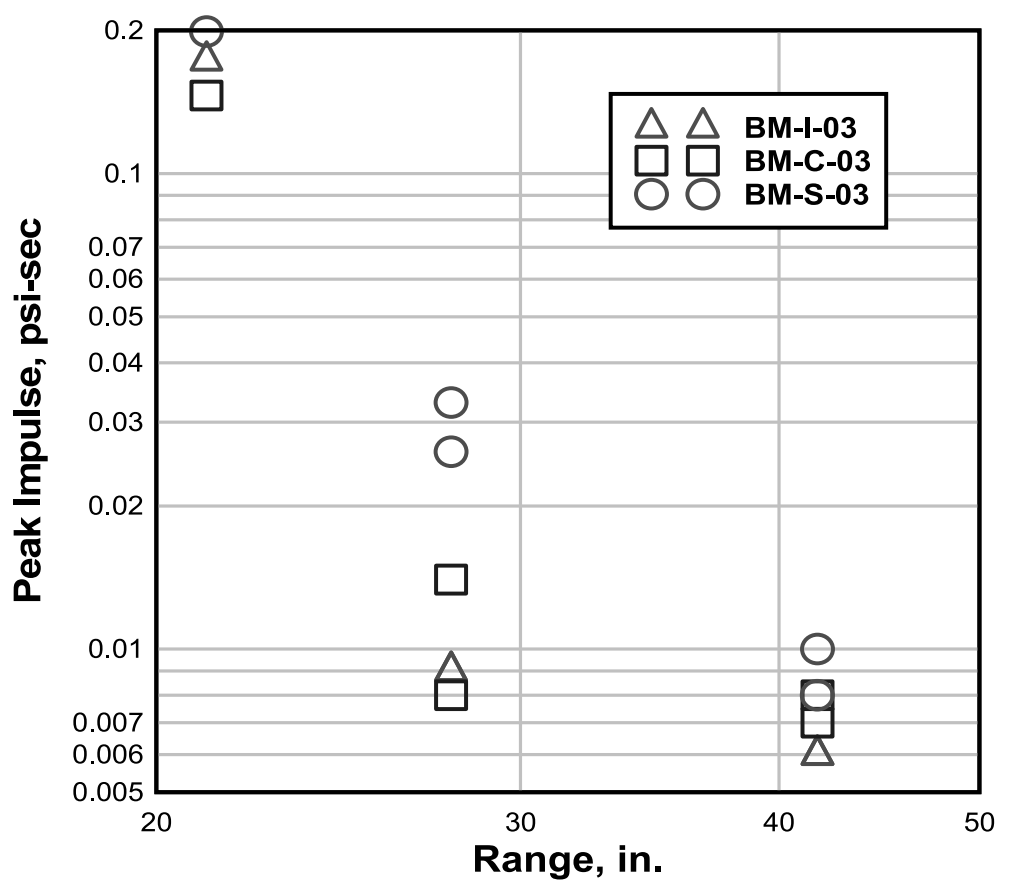

Fig. 13. Peak side-on overpressure impulse for the charge buried 4 in. 
Table 4

Peak total impulse imparted to the IMD

\begin{tabular}{lcc}
\hline Backfill Material & \multicolumn{2}{c}{ Peak Impulse, lbf-sec } \\
\cline { 2 - 3 } & Charge TSA* & Charge Buried 4 in. \\
\hline Intermediate Silty Sand (SM) & 545 & 1880 \\
Sandy Clay (CL) & 650 & 2610 \\
Poorly Graded Sand (SP) & 619 & 1635 \\
\hline
\end{tabular}

* Tangent surface above.

At the 21- and 42-in. ranges, all peak impulse values decayed, but at different rates. At the 21-in. range, the sand testbed case was significantly greater than the intermediate and clay testbeds. At the 42 -in range, the sand testbed was only slightly greater than the intermediate and clay testbeds.

When the peak impulse values for the tangent surface above case, Fig. 11, are compared to the tangent surface below case, Fig. 12, the peak values at the two closest ranges are similar. The data at the closest range in Fig. 12 may be slightly higher than the comparable data in Fig. 11, but additional experimental results would be required to confirm this. At the 42-in. range, the peak impulse data for the tangent surface below charge location are about half the values for the tangent surface above charge location. This potentially slight increase at the closest range and reduction in peaks at the outer ranges seem to indicate that a small amount of focusing occurred for the tangent surface below charge location compared with the case for tangent surface above charge location. This is consistent with the increased lateral confinement for the tangent surface below charge placement.

For the buried charge case, Fig. 13, the values of peak impulse at the 21-in. range (from center of charge to center of gage directly above the charge) are about twice the values for the tangent surface above cases, Fig. 11. At the 28-in. range, the peak impulse values for the intermediate soil and the clay are about a third of the comparable values for the tangent surface above case. Also, for the buried charge case at approximately the 28 -in. range from the explosive charge, the sand values for peak impulse are about three times those for the other two soil types. At the 42-in. range, the peak impulse values from the buried charge experiments are about half those from the tangent surface below experiments (Fig. 12) and about a third or more of the peak impulses from the tangent surface above experiments (Fig. 11). Again, this increased peak impulse directly above the charge (21-in. range) and the reduction in impulse at the 28- and 42-in. ranges appear to indicate a focusing effect above the charge. The variation in this focusing appears to be affected by soil type. The clay and intermediate soil responded in a similar manner at the 28-in. range (Fig. 13), while the sand appeared to be less influenced.

\subsection{IMD peak impulse}

The calculated values of peak impulse imparted to the IMD are compared in Table 4. Peak impulse from the buried charges exceeded the peak impulse from the surface charge positions by factors ranging from 2.6 to 4 . For both explosive charge positions, peak impulse from the experiments in the clay testbeds was higher than from experiments in the intermediate silty sand and sand testbeds. For the case of the tangent surface above charge position, peak impulse from the clay testbed experiments was 5\% and 20\% higher than the peak impulses imparted in the sand and silty sand testbeds, respectively. For the buried charge case, these differences were $60 \%$ and $40 \%$, respectively.

\subsection{Impulse versus charge depth of burial}

The total peak impulse captured by the IMD versus the depth at the center of the charge below the surface for the three soil types is shown in Fig. 14. The two configurations included in the figure are for the explosive charge placed on the surface, or tangent surface above the testbed, and the buried charge. For plotting purposes, the surface charge is shown with a depth of 0 . There is no indication in Fig. 14 that the underlying material affected the total impulse for the surface detonation. However, the total impulse for the buried charge was significantly higher for the clay soil compared to that for both the sand and silty sand. Figure 15 shows the peak impulse from the side-on overpressure airblast gage directly above the charge versus the depth of the center of the charge below the surface for the three soil types. Similar to Fig. 14, there is no significant indication that the underlying material affected the airblast impulse for the surface detonation. For the buried charge, there was indication that the surrounding soil affected the airblast 


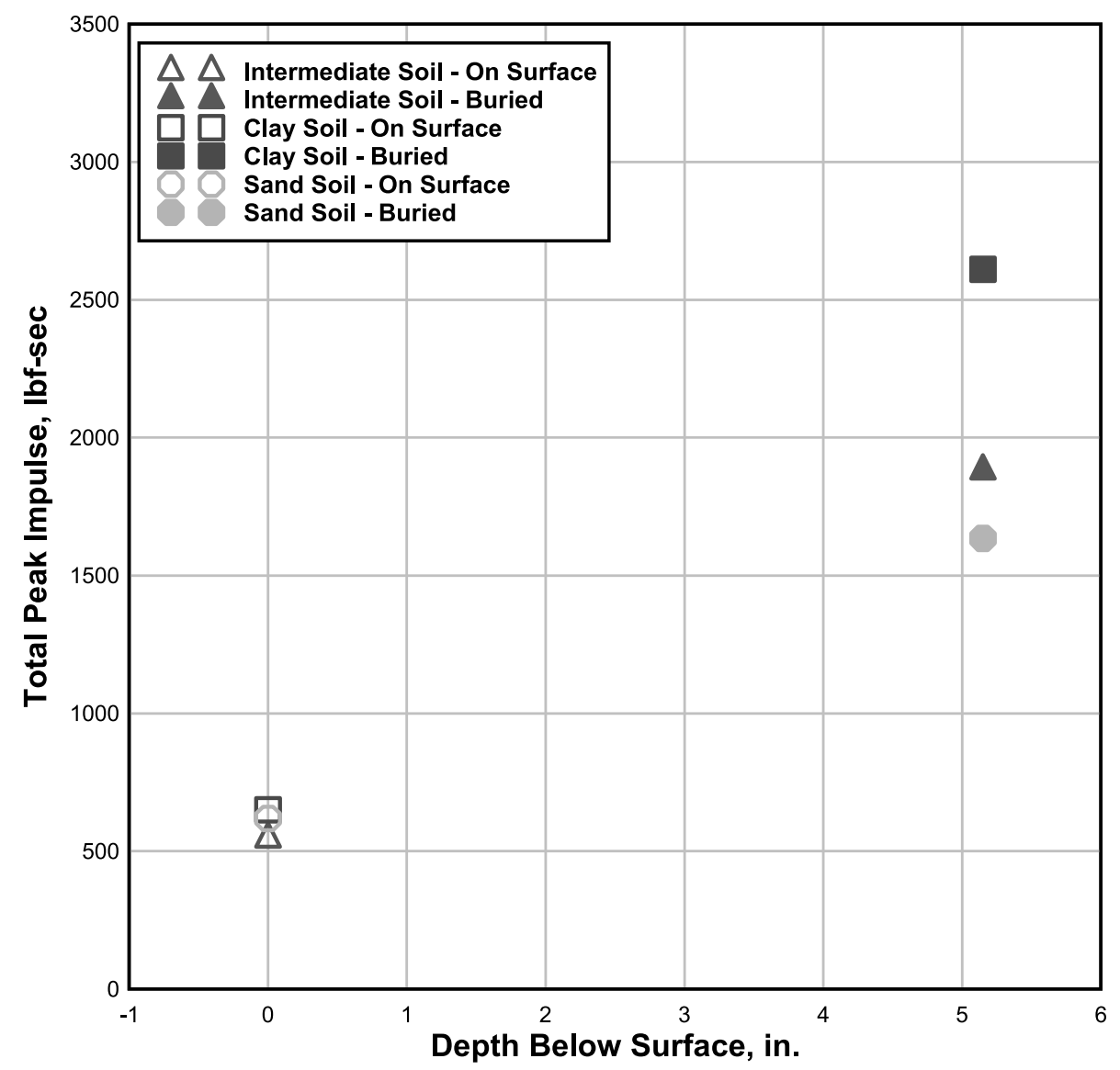

Fig. 14. Total impulse from IMD versus depth of burial to charge CG.

impulse, but the results were opposite of those shown in Fig. 14, with the clay providing the lowest airblast impulse and the sand providing the highest. Like the total IMD impulse, the airblast impulse increased from surface laid to shallow buried at the center-gage location.

\section{Comparison analysis}

After completing the field experiments, the representative bulk soil samples from each of the testbeds were brought back to the laboratory, and detailed material property characterizations were performed. Table 3 provided the as-placed testbed soil parameters for the three soil types. These soil parameters were used along with the total IMD impulse and the peak airblast impulse at the center gage to perform comparative analyses. Of the parameters investigated, two provided a significant influence on the total impulse; volume of air and percent fines. Figure 16 shows the total IMD peak impulse and peak airblast impulse at the center gage from buried charges versus the volume of air. As the volume of air decreases, the total IMD impulse increases (Fig. 16a). This is directly related to the decreasing compressibility and shear strength in the soil. Also as the volume of air increases, the peak airblast impulse increases, but at a much lower rate (Fig. 16b). These results reflect differences in the mechanical and permeability properties of the soil. As the soil air voids content increases, the soil shear strength, compressibility, and permeability are all increasing. Also as the crater size increased from sand to intermediate silty sand to clay for the same charge location (Figs 8 through 10), the total impulse increased, and the peak airblast impulse decreased.

Figure 17 shows the total IMD peak impulse and peak airblast impulse at the center gage from buried charges versus the percent fines in the soil. As the percent fines increase, the total IMD impulse increases (Fig. 17a). Again, 


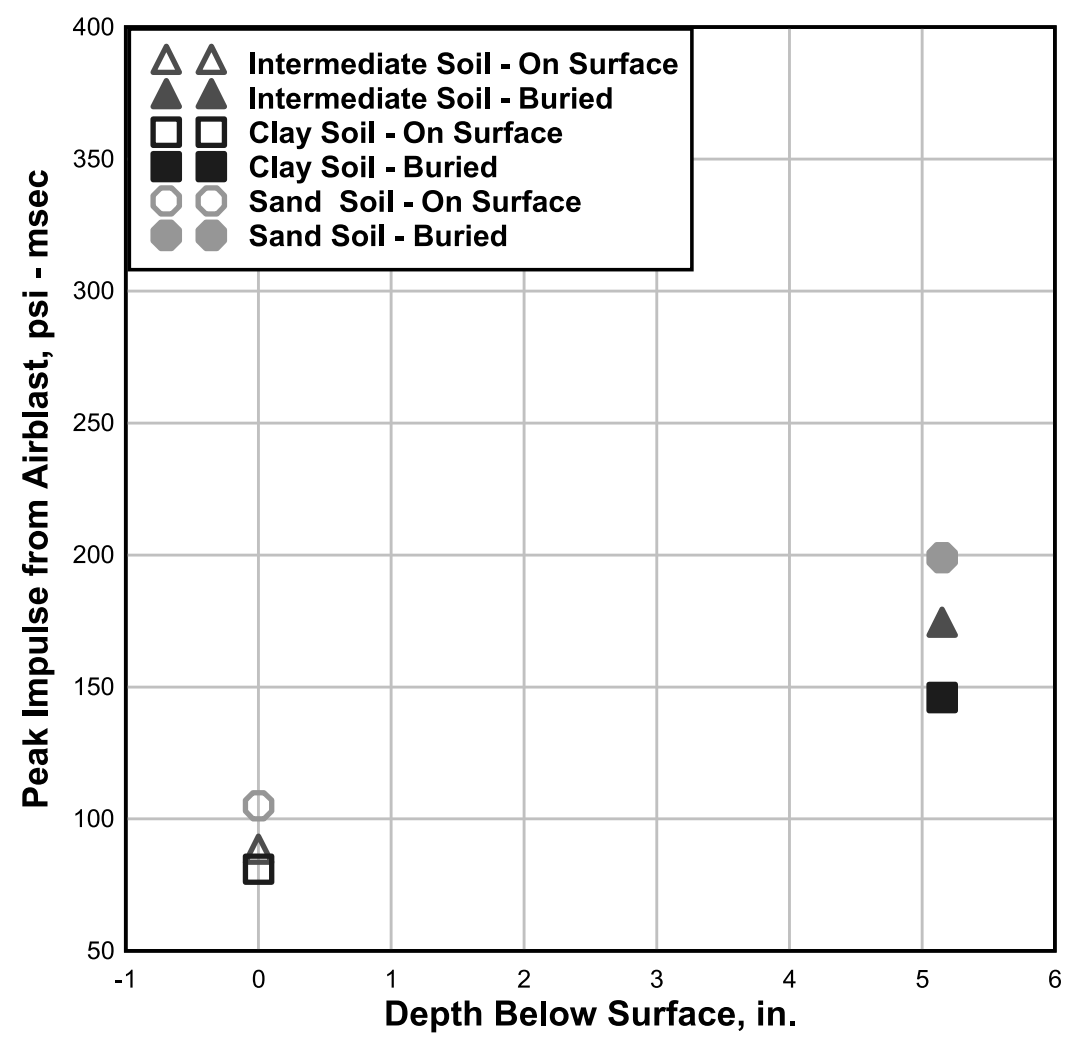

Fig. 15. Peak impulse from side-on overpressure gages versus depth of burial to charge CG.

this is directly related to the decreasing compressibility and shear strength in the soil. Also, as the percent fines increases, the peak airblast impulse decreases (Fig. 17b). The result reflects differences in mechanical properties of the soils. As the soil air voids content increases, the soil shear strength, compressibility, and permeability are all increasing. For the detonation in the sand, the energy is dissipated by the high compressibility (caused by the $29.8 \%$ air-filled voids) and by the air escaping the sand matrix due to the high permeability $\left(10^{-1}\right.$ to $\left.10^{-3} \mathrm{~cm} / \mathrm{sec}\right)$. Both the high compressibility and high permeability, in addition to the high shear strength, caused the craters in the sand to be smaller. The high permeability in the sand caused a faster expulsion of airblast from the sand for the buried detonation resulting in greater aboveground airblast, i.e., more energy goes into airblast and less in driving sand debris particles. In contrast, the wet clay with low compressibility, permeability, and shear strength produced larger craters and less aboveground airblast, and more energy is directed towards driving clay debris particles. There were no repeat tests conducted under this program due to limited funding at the time. Therefore, data to show the variations of primary measured results due to the failure to exactly replicate experiments are not available. Future experiments are planned to address this issue.

\section{Summary and conclusions}

A device for determining the aboveground impulse (impulse measuring device (IMD)) due to the detonation of surface and buried explosives was designed, fabricated, calibrated, and deployed in a series of experiments for the purpose of quantifying the effects of three very different soil types on the impulse delivered to aboveground structures. The soil types included wet sandy clay, dry sand, and an intermediate air-void, silty sand. The backfill materials were placed for each experiment so that variations in as-placed water content and dry density for each soil type were minimized based on results of field quality control test results. The 5-lb cylindrical (mine-shaped) 


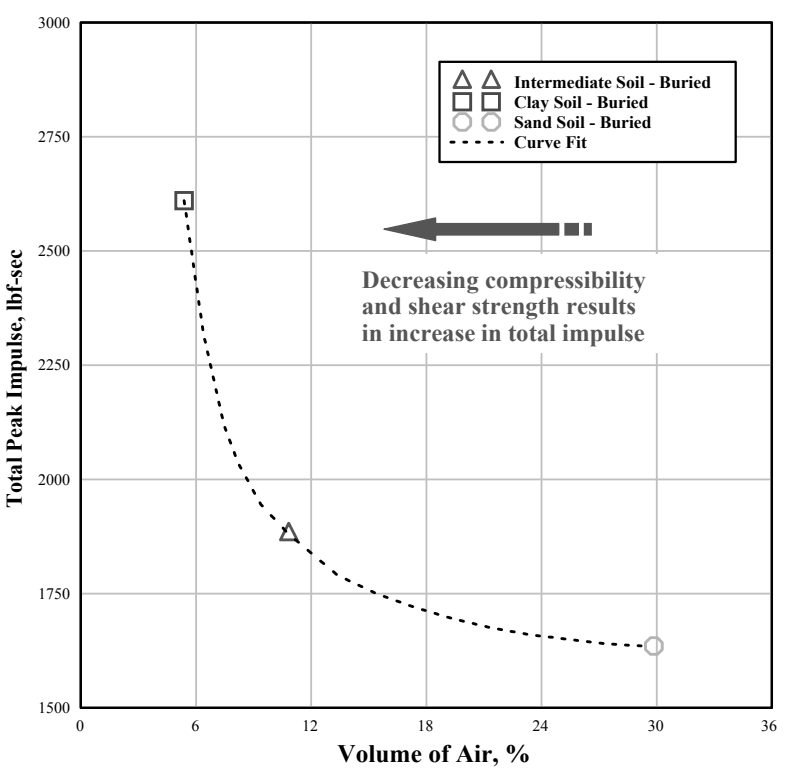

a. Total impulse versus volume of air.

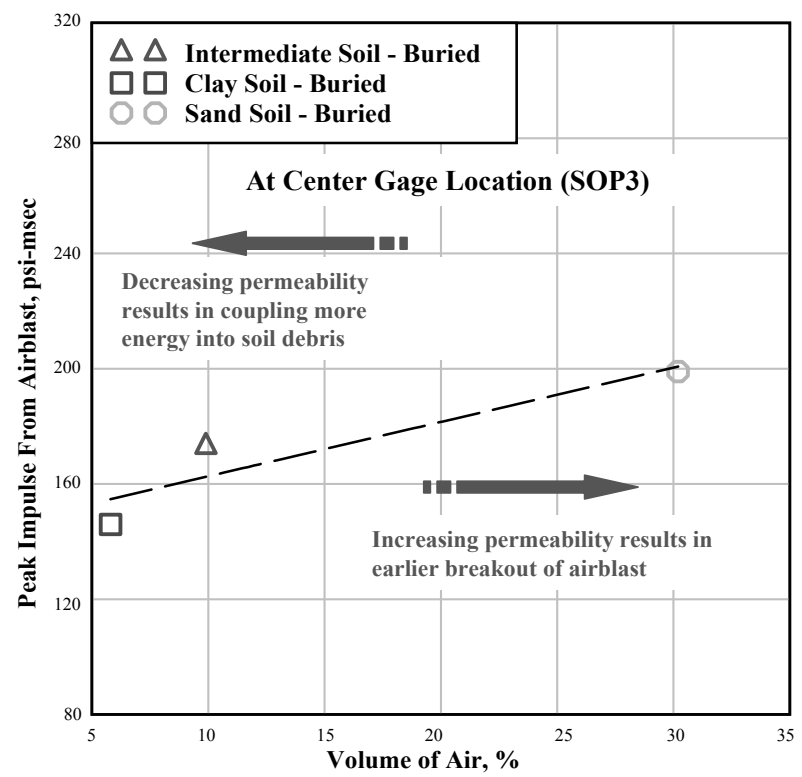

b. Peak airblast impulse versus volume of air.

Fig. 16. Total IMD peak impulse and peak airblast impulse versus the volume of air.

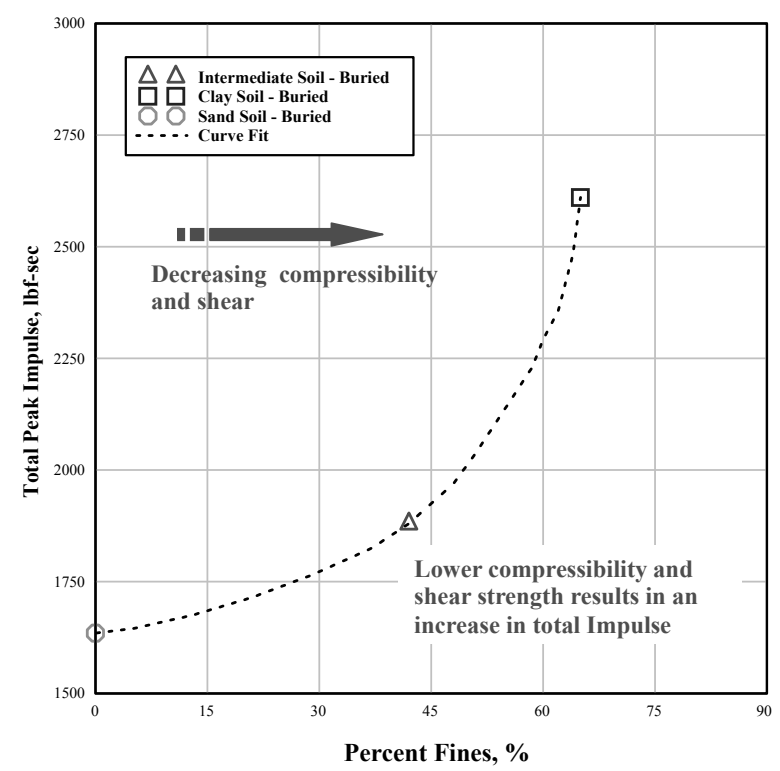

a. Total impulse versus percent fines.

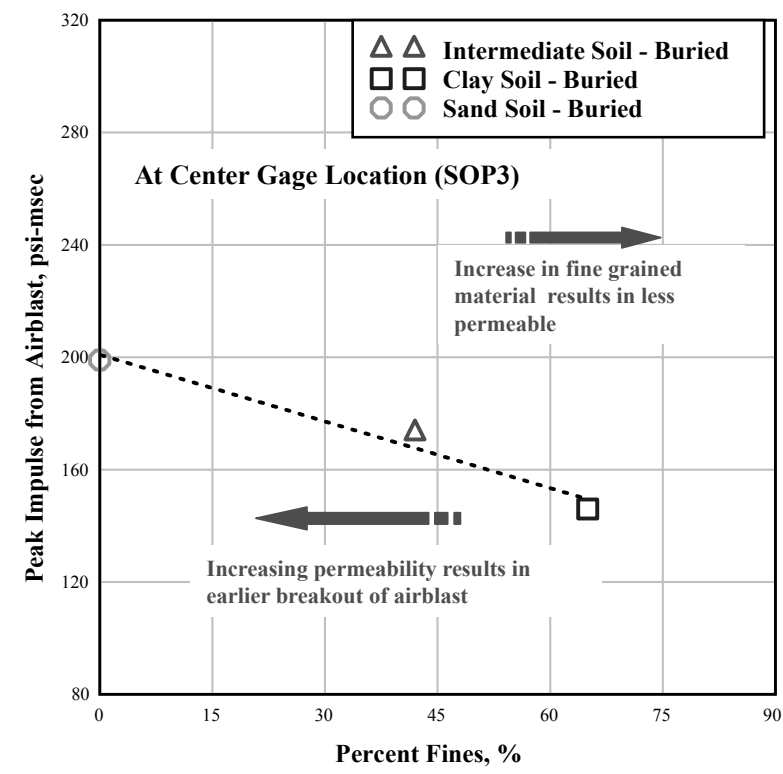

b. Peak airblast impulse versus percent fines.

Fig. 17. Total IMD peak impulse and peak airblast impulse versus the percent fines in the soil.

explosives were placed on the surfaces of the testbeds (tangent surface above), buried so that the top of the explosives were flush with the top of the testbeds (tangent surface below), and buried with the top of the explosive 4 in. below the testbed surface. The standoff distance between the top of the explosive charges and the face of the IMD impact plate was held constant at 20 in.

The sizes of the soil craters increased as the depth of the explosive increased. The crater depth and slopes were significantly affected by soil type. The clay craters had the greatest depths and the steepest side slopes for all charge 
positions. The sand craters had the shallowest depths and flattest side slopes. The two soil parameters that were consistent with these results were air-voids content and shear strength. As the air-voids content and shear strength increased, the crater depth decreased and side slopes flattened.

The peak side-on overpressure impulse values at the 21 -in. range (center of the testbeds) from the buried charge experiments were about twice the values obtained from the surface charge experiments. At the 28-in. range, the sand values for peak airblast impulse for the buried charge case were about three times those for the other two soil types, which in turn were about a third of their comparable values for the surface charge cases. At the 42-in. range, peak airblast impulse values from the buried charge experiments were about half those from the tangent surface below experiments and about a third or more of the peak impulses from the tangent surface above experiments. This increased peak airblast impulse directly above the charge (21-in. range) and the reduction in impulse at the 28- and 42-in. ranges appears to indicate a focusing effect above the charge. The variation in this focusing appears to be affected by soil type, in that the clay and intermediate silty sand responded in a similar manner at the 28-in. range in the buried charge case, while the sand appeared to be less influenced. This apparent focusing of the overpressure impulse seems to be caused by lateral confinement of the explosive charge, which indicates that the sand material provided less lateral confinement than did the silty sand and clay soils. This phenomenon was well illustrated by comparisons of the craters for the three different soil materials used in these experiments, in that the sand craters had the shallowest depths and flattest side slopes, while craters for the other two materials were deeper and had steeper side slopes.

Peak total impulse imparted to the IMD from the buried charges exceeded the peak total impulses from the tangent surface above charges by factors ranging from 2.6 to 4 . For both explosive charge positions, peak total impulse from the experiments in the clay testbeds was higher than those from experiments in the intermediate silty sand and sand testbeds. For the case of the tangent surface above charge position, peak total impulse from the clay testbed experiments was $5 \%$ and $20 \%$ higher than the peak total impulses imparted in the sand and silty sand testbeds, respectively. For the buried charge case, these differences were $60 \%$ and $40 \%$, respectively.

The magnitude of aboveground airblast, soil debris, and total impulse delivered to the aboveground IMD due to the detonation of cylindrical surface-laid bare explosive charges were minimally affected by the mechanical properties of the underlying material, e.g., low and high air-voids soils. However, the magnitude of aboveground airblast, soil debris, and total impulse increased significantly for shallow-buried charges and were significantly influenced by the soil properties compared to charges on the surface. The soil properties of specific interest included the volume of air, the percent fines, and permeability. The total peak impulse decreased as the volume of air increased, but the airblast-induced peak impulse increased as the volume of air increased. Total peak impulse also increased as the percent fines (silts and clays) increased, but airblast-induced peak impulse decreased as the percent fines increased. This seems to indicate that for a shallow-buried charge detonated in a high-air-voids, permeable dry sand material, airblast breaks out early resulting in increased airblast impulse, reduced soil debris loading, and thus, reduced total impulse.

This initial series of IMD experiments was very successful in quantifying the airblast impulse and total impulse imparted to an aboveground structure. Effects of varying soil materials and charge depth of burial were observed. Additional experiments of this type, including repeat experiments, need to be conducted so that improved quantification of the effects of these variables can be made, which in turn will significantly improve the analysis and design of aboveground structures subjected to surface and near-surface detonations.

\section{Acknowledgement}

The authors express appreciation and acknowledgement to the U.S. Army Engineer Research and Development Center (ERDC) and U.S. Army Tank Automotive Research, Development and Engineering Center (TARDEC) for funding and support of this research.

\section{References}

[1] M. Grujicic, B. Pandurangan and B.A. Cheeseman, The effect of degrees of saturation of sand on detonation phenomena associated with shallow-buried and ground-laid mines, Shock and Vibration Journal 13 (2006). 
[2] S.L. Hlady, Effect of Soil Parameters on Landmine Blast, 18th Military Aspects of Blast and Shock (MABS) Conference, Mannheim, Germany, 2004.

[3] M. Held, Calibration Tests for Blast Impulse Loads on Anti-Tank Mines, 17th Military Aspects of Blast and Shock (MABS) Conference, Las Vegas, NV, 2002.

[4] A.B. Wenzel and E.D. Esparza, Measurement of Pressure and Impulse at Close Distance from Explosive Charges Buried and in Air, U.S. Army Mobility Equipment Research and Development Center, Fort Belvoir, VA, 1972.

[5] E.M. Williams, J.E. Windham, J.Q. Ehrgott, Jr., K.T. Danielson and D.J. Gorsich, Effect of soil properties on an aboveground blast environment from buried bare charges, Proceedings of the 20th Military Aspects of Blast and Shock (MABS) Conference, Olso, Norway, 2008.

[6] US Army Corps of Engineers, Laboratory Soils Testing, Engineering Manual EM-1110-2-1906, Washington, DC, 1980.

[7] US Army Engineer Waterways Experiment Station, The Unified Soil Classification System, Technical Memorandum No. 3-357, Vicksburg, MS, 1960.

[8] J.Q. Ehrgott, Jr., E.M. Williams, J.E. Windham, S.A. Akers, M.D. Adley, S.S. Graham and P.A. Reed, Tactical wheeled vehicle survivability: construction and characterization of intermediate- air-voids, silty sand testbeds in bare charge experiments," ERDC/GSL TR-10-16, US Army Engineer Research and Development Center, Vicksburg, MS, 2010.

[9] J.Q. Ehrgott, Jr., E.M. Williams, J.E. Windham, S.A. Akers, M.D. Adley, S.S. Graham and P.A. Reed, Tactical wheeled vehicle survivability: construction and characterization of dry sand testbeds in bare charge experiments, ERDC/GSL TR-10-15, US Army Engineer Research and Development Center, Vicksburg, MS, 2010.

[10] J.Q. Ehrgott, Jr., E.M. Williams, J.E. Windham, S.A. Akers, M.D. Adley, S.S. Graham and P.A. Reed, Tactical wheeled vehicle survivability: construction and characterization of wet clay testbeds in bare charge experiments, ERDC/GSL TR-10-17, US Army Engineer Research and Development Center, Vicksburg, MS, 2010.

[11] A.R. Jumikis, 1962 Soil Mechanics, Yan Nostrand, Princeton, N5, p. 211.

[12] J.Q. Ehrgott, Jr., Tactical wheeled vehicle survivability: results of experiments to quantify aboveground impulse, ERDC/GSL TR-10-7, US Army Engineer Research and Development Center, Vicksburg, MS, 2010. 

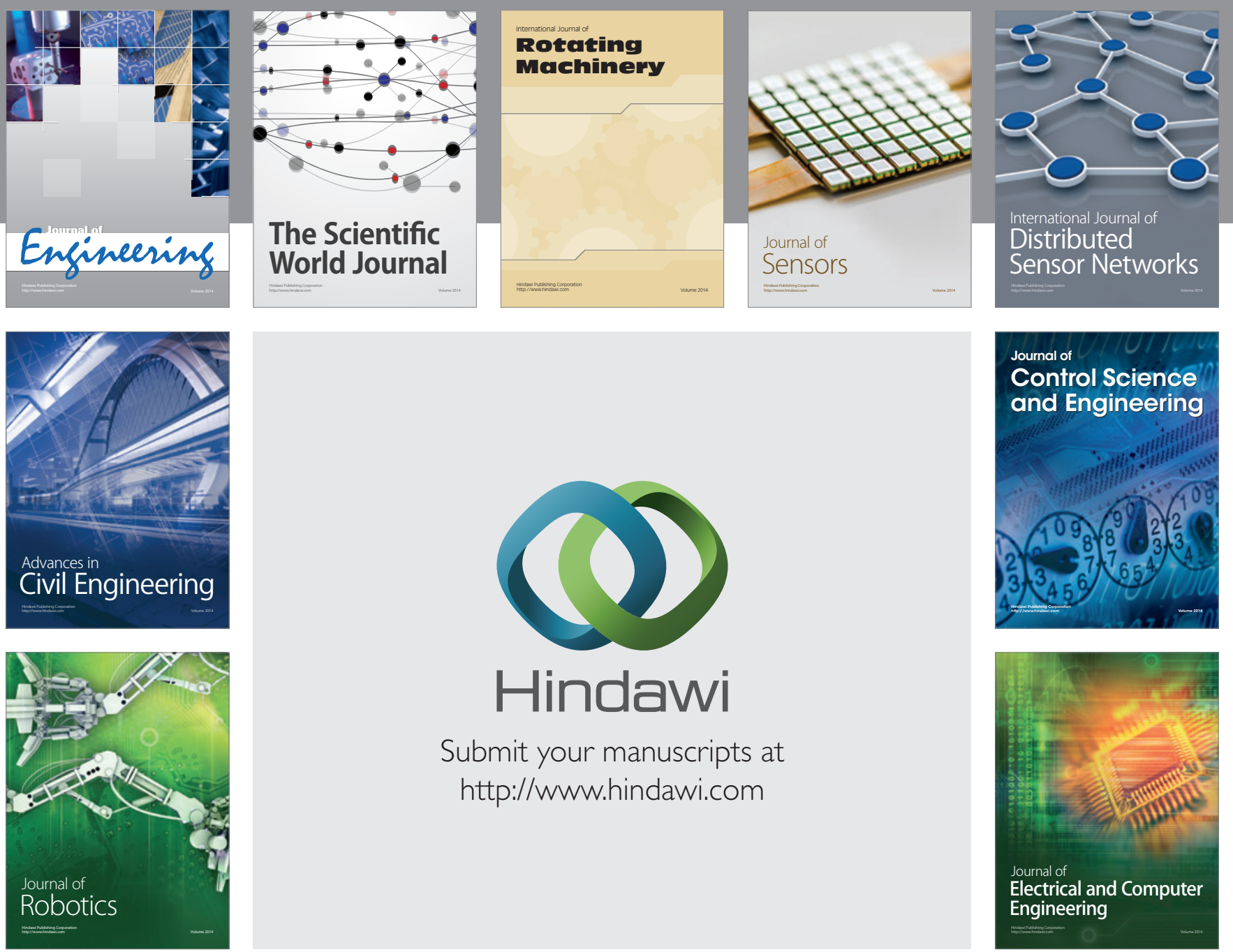

Submit your manuscripts at

http://www.hindawi.com
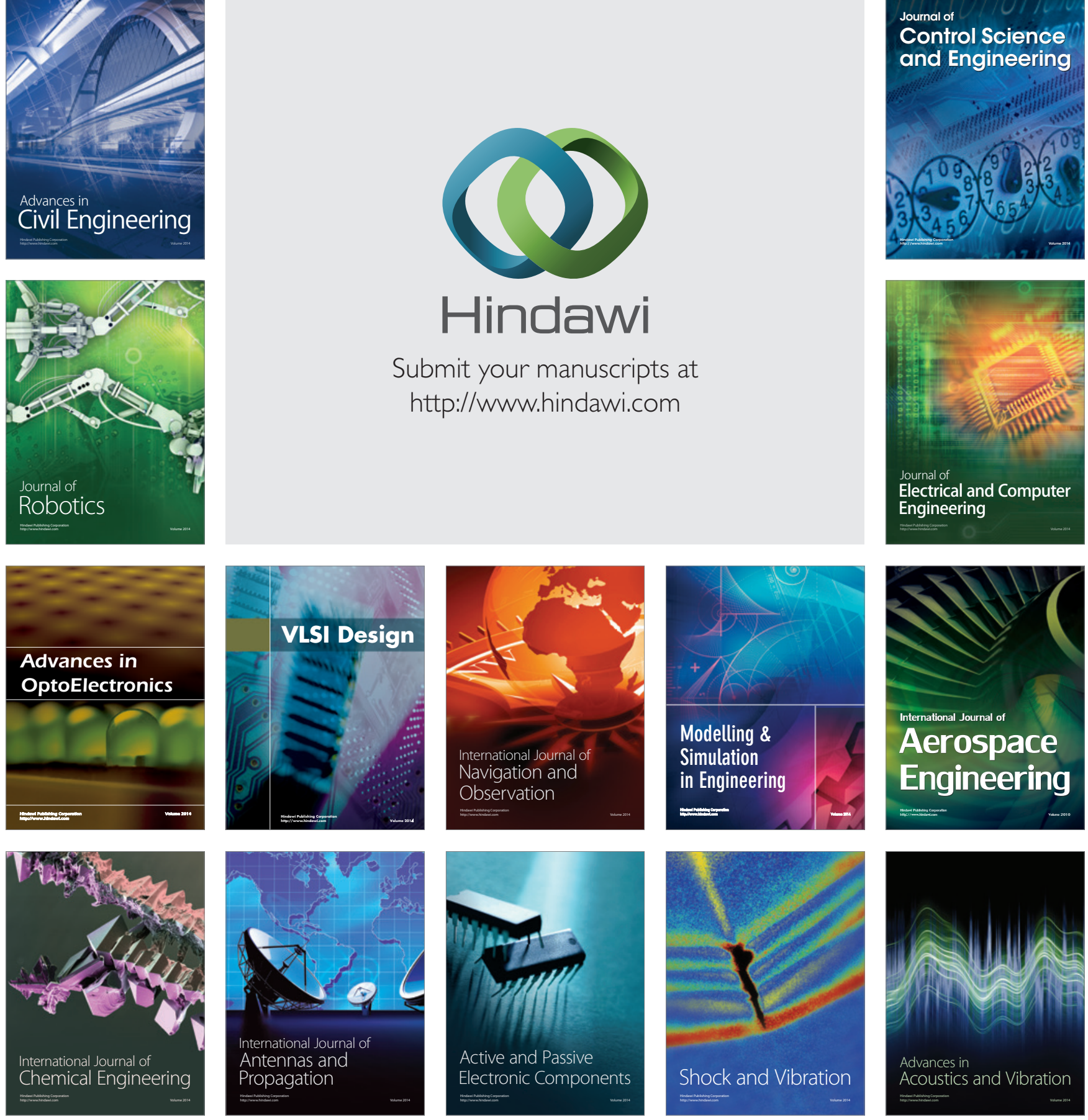